\title{
Metric and Non metric characteristics of human forefoot: radiological study in Egyptian population
}

\author{
Samah Mohammed, Mahmoud Abozaid and Fatma Elzahraa, Fouad Abd Elbaky
}

Department of Anatomy, Faculty of medicine, Minia University, Minia, Egypt.

Correspondence Author: Samah Mohammed, Department of Anatomy, Faculty of medicine, Minia University, Minia, Egypt.

Received date: 1 January 2019, Accepted date: 15 January 2018, Online date: 28 February 2019

Copyright: (C) 2019 Samah Mohammed et al, This is an open-access article distributed under the terms of the Creative Commons Attribution License, which permits unrestricted use, distribution, and reproduction in any medium, provided the original author and source are credited.

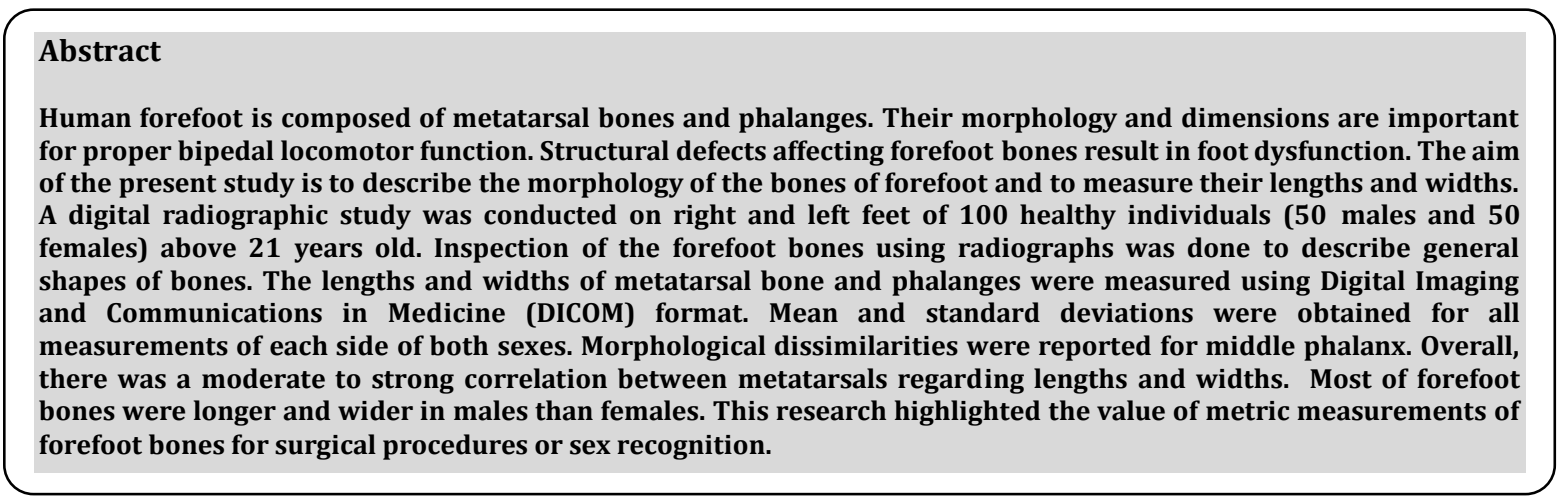

Key words: forefoot, metric, radiology, Egyptian population.

\section{INTRODUCTION}

Human foot is a highly modified distal portion of lower limb. It is responsible for stepping, walking and running (Mann, 1999) and weight bearing (Viladot, 1973). The human foot is comprised of bone, joints, muscles and fascia. The integrity of these structures keep it perform its function properly (Mann, 1999). The foot is divided anatomically from anterior to posterior into three parts; the forefoot, the midfoot and the hindfoot. The forefoot part is composed of five proximal bones called metatarsals and more distal bones called phalanges (Nawoczenski et al., 1998). The metatarsals bear weight through its heads. The first metatarsal bears double the weight of each of the other four metatarsals. The weight is distributed in the ratio of 2:1:1:1:1 (Viladot, 1973). Any deviation from this normal ratio impairs foot function (Nawoczenski et al., 1998). The morphological appearance of phalanges adapts the foot for bipedal locomotor function (Rolian et al., 2009). Characteristically the phalanges have a variable morphological appearance (Keat and Anderson, 2013). Structural defects of the foot may be isolated defects as congenital Talipes Equinovarus (Al Abdulwahab and Kachanathu, 2015), part of a complex syndrome (Mann, 1999) or trauma (Nawoczenski et al., 1998). The coexistence of both metatarsal and metacarpal defects in same subject may raise the possibility of having syndrome (Green et al., 1989). Industrial trauma to the metatarsals is very common to the first and second metatarsal bones (Lamm, 2006). Disturbance in the relative lengths and widths of the bony components of the forefoot may lead to pain in the feet, gait disturbances and locomotor dysfunction (Murphy, 2013) secondary to corns, calluses and arthritis formation that impair foot function (Mann, 1999). Restoring the proper lengths and widths of the metatarsals and phalanges is important for optimal surgical outcome (Lamm, 2006). In surgery metatarsal lengthening or shortening is aiming to achieve a length that function in a proper manner (Lamm et al., 2009). Knowing the lengths or widths of the metatarsals and phalanges and their correlation among themselves may be of value for sex determination, surgical procedures such as lengthening or shortening of the metatarsal and phalanx bone or describing the affected bone length or width in congenital skeletal abnormalities (Dogan et al., 2007).

The aim of the present study was to describe the shape of the bone forming forefoot and to measure the lengths and widths of both metatarsals and phalanges of the forefeet on standardized radiographs and to determine the possible correlation between the forefoot bones amongst themselves and their value for surgical implication or sex determination.

\section{METHODS}


This digital radiographic study was conducted on both right and left feet of 100 healthy individuals (50 males and 50 females) above 21 years old (To ensure complete bone ossification). AP radiographs of both feet were done at the same time. A consent form was obtained from each participant before this procedure.

Exclusion criteria include subjects less 21 years old, history of feet problems such as trauma or surgical operations in lower limb. The radiograph was taken while the patient in supine position with flexed knee. The planter surface of foot was placed in a flat firm manner on the cassette. Lead shield was put over pelvic region. The collimation was done to outer margins of foot on four sides. The central ray was angled 10 degree posteriorly towards the calcaneus and centered on and perpendicular to the base of 3rd metatarsal, the FFD $=100 \mathrm{~cm}$. the technical factors were $70 \mathrm{KV}$ and $2 \mathrm{mAs}$.

Digital Imaging and Communications in Medicine (DICOM) format was used as a tool for measuring lengths and widths of forefoot bones. Radiographs were viewed using RadiAntDicom viewing software (32 bit) with magnification and measuring tools (ver. 1.0.4.4439, Copyright 2009-2012 Medixant) (fig. 1). For length determination a midpoint of base and a midpoint of head of metatarsal bone and phalanges were localized and the length of the line between these two points was measured.

For width determination a midpoint (the length of corresponding bone divided by two) were localized on both medial and lateral sides of bone and the length of the line between these two points was measured and recorded. Inspection of the forefoot bones using radiographs was done to describe general shapes and borders of the bones and its similarity or variation among themselves

\section{Statistical Analysis}

The data were analyzed using SPSS statistical package version 20. One sample Kolmogorov-Smirnov test was used to detect the distribution of data and according to the result of this test, the suitable test was chosen. Descriptive statistical measures, including measures of central tendency (mean) and dispersion (SD), were used to describe the data. Mean and standard deviations of each variable were calculated for both sides of both sexes. Student-t test was done to establish the presence or absence of significant sexual differences by side. $P$ values $<0.05$ were considered statistically significant . The association between metatarsal lengths and widths was assessed using Pearson's correlation coefficient.



Fig.1: showing the measuring tool for forefoot bones using Radiant DICOM viewer for length (A) and width (B).

\section{RESULTS}

A digital radiographic examination of individuals aged between 27 and 41 years was done in the present study.

Morphological (Non- metric) analysis

Metatarsals (Mt):

They showed concave medial and lateral margins. There was no morphological variation concerning metatarsals margins among themselves. The length of the bone was much greater than its width (elongated type) 
Citation: Samah Mohammed, et al., Metric and Non metric characteristics of human forefoot: A radiological study in Egyptian population. Australian Journal of Basic and Applied Sciences, 13(2): 46-54. DOI: 10.22587/ajbas.2019.13.2.6

Proximal phalanges (PP):

They showed concave medial and lateral margins. There was no morphological variation concerning PP margins among themselves. The length of the bone was greater than its width (elongated type).

Middle phalanges (MP):

The medial and lateral margins of this bone may be concave or flattened. The length of the bone may be greater than its width, equal or even less. Variable appearance of MP leads to description of middle phalanx as elongated type (L variety) if anteroposterior distance is greater than transverse one or shortened type ( $\mathrm{S}$ variety) if anteroposterior distance is equal or less than transverse distance.

In the present study the 5 th toe never had elongated type. Also absence of middle phalanges was reported for $4^{\text {th }}$ and $5^{\text {th }}$ toes.

Pattern of variable appearance of MP: (Fig.2-5)

In the present study MP may show:

Elongated MP from $2^{\text {nd }}$ digit to $4^{\text {th }}$ one with shortened type in $5^{\text {th }}$ digit (3L 1S) (Fig. 2A)

Elongated MP in $2^{\text {nd }}$ digit and $3^{\text {th }}$ one with shortened type in $4^{\text {th }}$ and $5^{\text {th }}$ digits (2L $\left.2 \mathrm{~S}\right)$ (Fig.2B)

Elongated MP in $2^{\text {nd }}$ digit only and shortened type from $3^{\text {rd }}$ to $5^{\text {th }}$ digits (1L 3S) (Fig.3A)

Shortened MP from $2^{\text {nd }}$ digit to $5^{\text {th }}$ digit (OL $\left.4 \mathrm{~S}\right)$ (Fig.3B)

No MP in $5^{\text {th }}$ digit. (Fig.4A)

No MP in $4^{\text {th }}$ digit and $5^{\text {th }}$ digit. (Fig.4B)

The MP of $5^{\text {th }}$ toe may appear round because of having biconvex lateral margins (R variety). (Fig.5)

Distal phalanges (DP):

They showed deeply curved medial and lateral margins. They have wide base and tapered distal end. There was no morphological variation concerning DP margins among themselves. The length of the bone was greater than its width (elongated type).
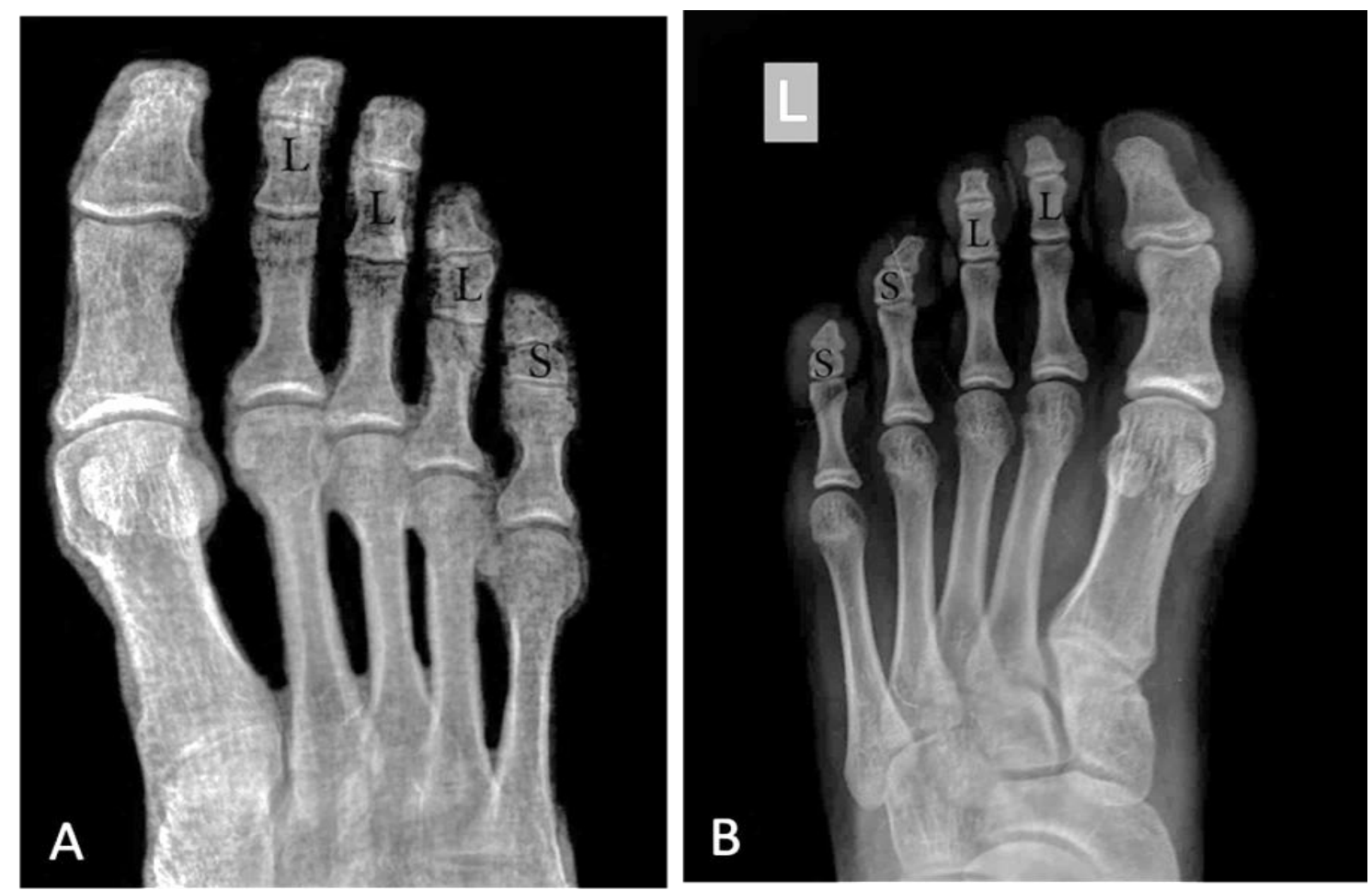

Fig. 2: showing (A) elongated type (L) of middle phalanx of $2^{\text {nd }}, 3^{\text {rd }}$ and $4^{\text {th }}$ digits and shortened $(\mathrm{S})$ type in $5^{\text {th }}$ one $(3 \mathrm{~L} 1 \mathrm{~S}$ pattern). In (B) elongated type (L) of middle phalanx of $2^{\text {nd }}$ and 3 rd digits and shortened (S) type in $4^{\text {th }}$ and $5^{\text {th }}$ one $(2 \mathrm{~L} 2 \mathrm{~S}$ pattern). 
Citation: Samah Mohammed, et al., Metric and Non metric characteristics of human forefoot: A radiological study in Egyptian population. Australian Journal of Basic and Applied Sciences, 13(2): 46-54. DOI: 10.22587/ajbas.2019.13.2.6
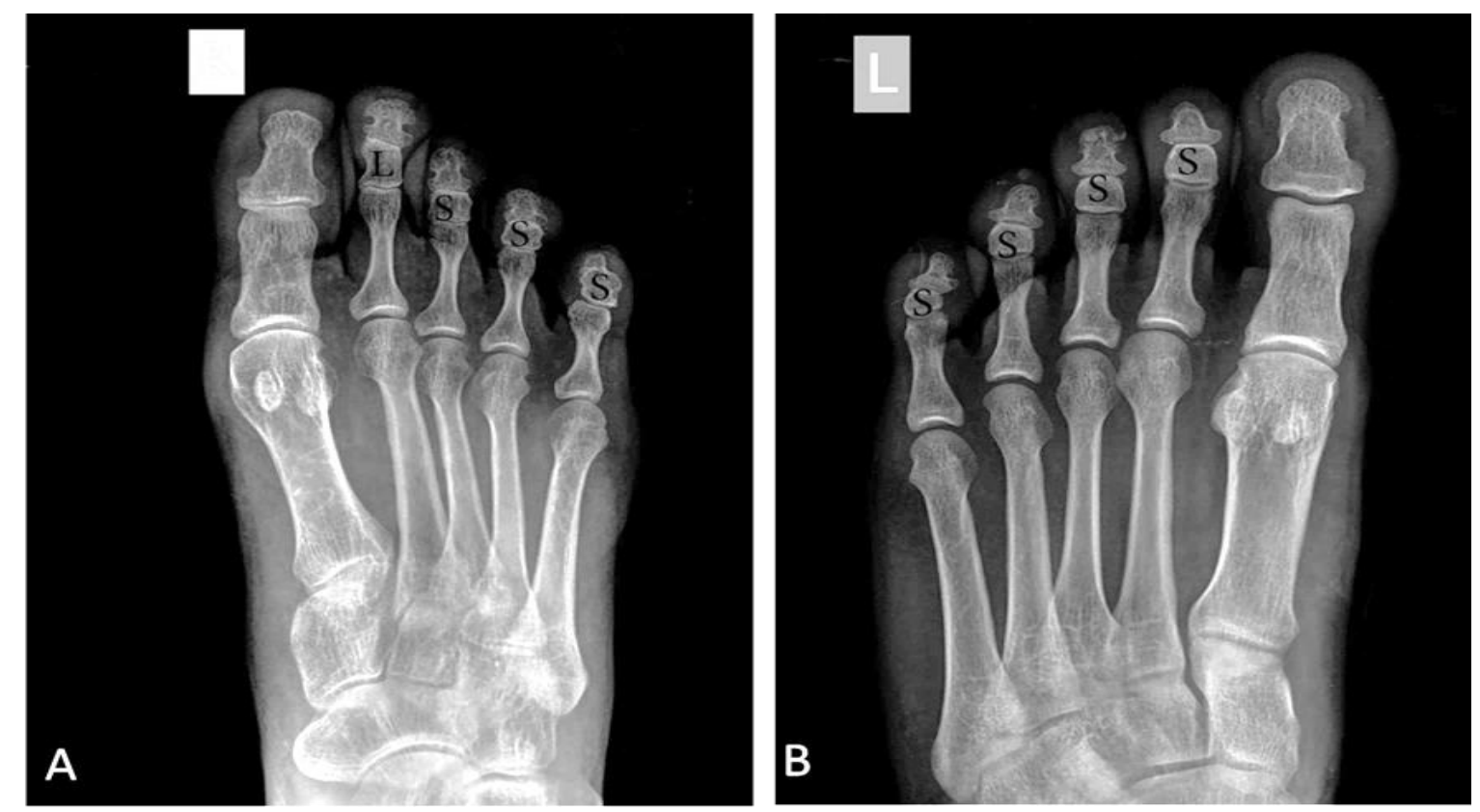

Fig. 3: showing (A) elongated type (L) of middle phalanx of $2^{\text {nd }}$ digit and shortened (S) type in $3^{\text {rd }}, 4$ th and $5^{\text {th }}$ one (1L $3 \mathrm{~S}$ pattern). In (B) shortened (S) type in all lateral four digits (0L 4S pattern).

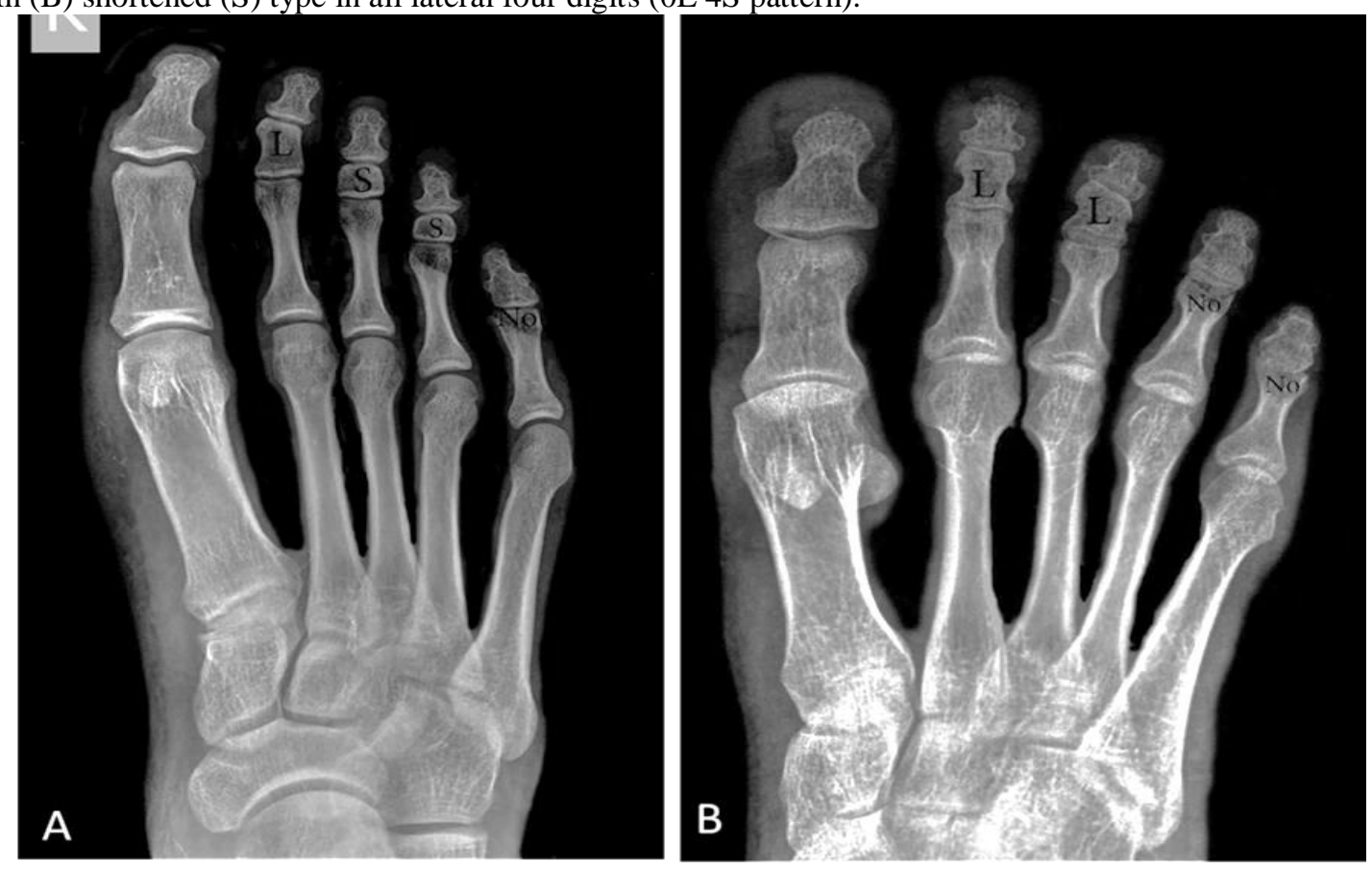

Fig. 4: showing (A) elongated type (L) of middle phalanx of $2^{\text {nd }}$ digit and shortened (S) type in $3^{\text {rd }}$ and $4^{\text {th }}$ one with no MP in $5^{\text {th }}$ toe $\left(1 \mathrm{~L} 2 \mathrm{~S}\right.$ pattern). In $(\mathrm{B})$ elongated type $(\mathrm{L})$ of MP of $2^{\text {nd }}$ and $3 \mathrm{rd}$ digits and no shortened $(\mathrm{S})$ type. There is no MP in both $4^{\text {th }}$ and $5^{\text {th }}$ digits (2L OS pattern). 

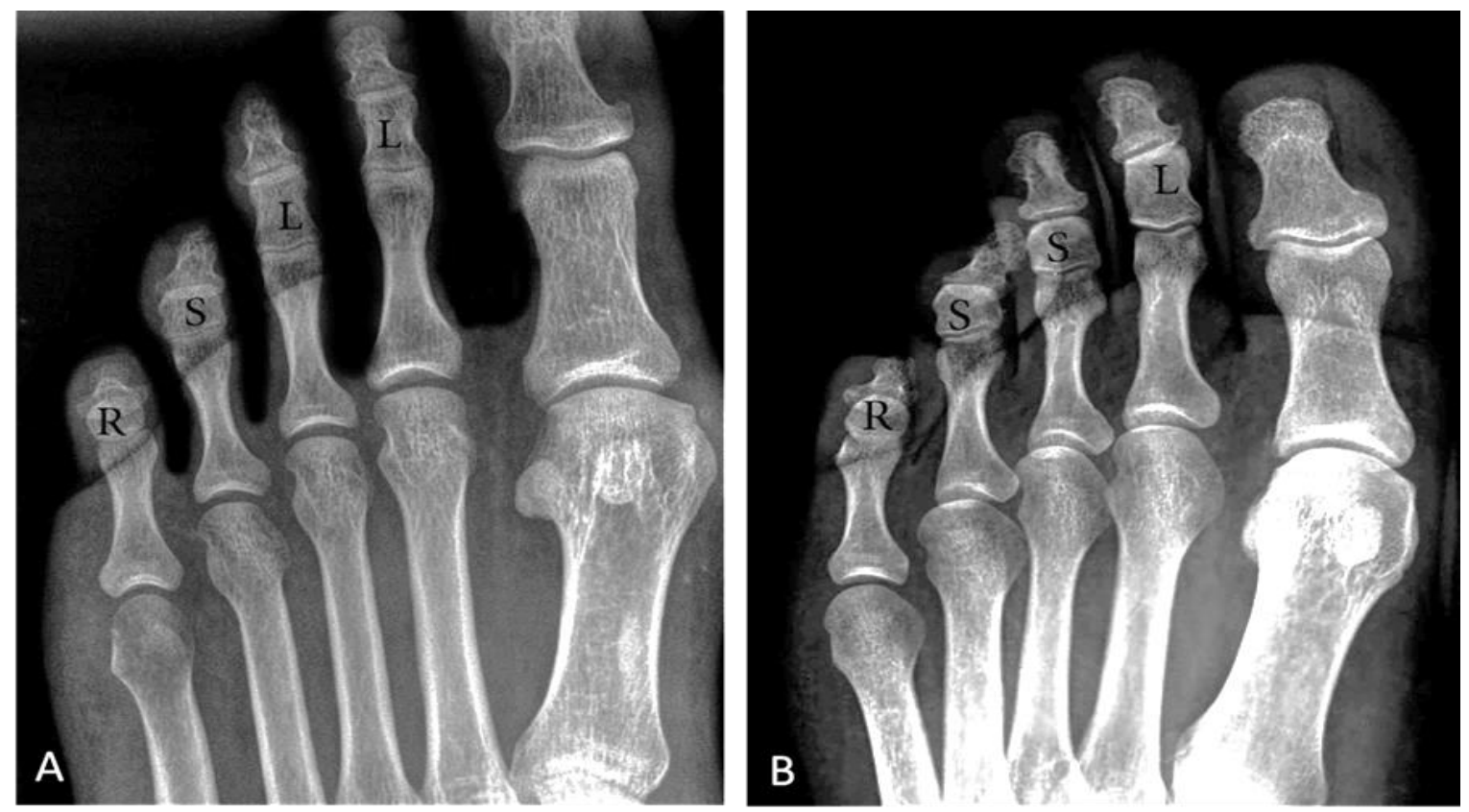

Fig. 5: showing (A) elongated type (L) of middle phalanx of $2^{\text {nd }}$ and $3^{\text {rd }}$ digits and shortened (S) type in $4^{\text {th }}$ one, rounded appearance of MP of $5^{\text {th }}$ digit (2L $1 \mathrm{~S} 1 \mathrm{R}$ pattern). In (B) elongated type (L) of MP of $2^{\text {nd }}$ digit, shortened (S) type in $3^{\text {rd }}$ and $4^{\text {th }}$ one and rounded appearance of MP of $5^{\text {th }}$ digit (1L $2 S$ 1R pattern)

For Lengths:

\section{METRIC ANALYSIS}

Measurement of the length of metatarsal revealed that the longest metatarsal in male subjects was Lt Mt2 followed by Rt Mt3 and shortest one was Lt Mt1. In Female subjects the longest metatarsal was Lt Mt3 followed by Lt Mt4 and the shortest was Lt Mt1. Statistical analysis of the metatarsal lengths for both sides of both sexes revealed that there are sex differences for all metatarsal lengths except Rt Mt2, Rt Mt3, Lt Mt4 and Rt Mt5 (Table 1). Measurement of the length of PP revealed that the longest PP in male subjects was Lt PP1 followed by Rt PP1 and shortest one was Rt PP5. In Female subjects the longest PP was Rt PP1 followed by Lt PP1 and the shortest was both Rt PP3 and Rt PP5. Measurement of the length of MP revealed that the longest MP in male subjects was Rt MP2 followed by Rt MP3 and shortest one was Rt MP5. In Female subjects the longest MP was Rt MP3 followed by Lt MP2 and the shortest was Lt MP5. Measurement of the length of DP revealed that the longest DP in male subjects was Lt DP1 followed by Rt DP1 and shortest one was Lt DP5. In Female subjects the longest DP was Rt DP1 followed by Lt DP1 and the shortest was Lt DP5. Statistical analysis of the phalangeal lengths for both sides of both sexes revealed that there are sex differences for all phalanges lengths except Lt PP1, Rt DP1, Rt PP2, Lt PP2, Rt MP3, Lt MP3and Rt DP5 (Table 1).

Table 1: Student t-test of the forefoot bones lengths for both sexes by side

\begin{tabular}{|l|l|l|l|l|l|l|}
\hline Variables & \multicolumn{2}{l}{$\begin{array}{l}\text { Males } \\
\text { mean } \pm \text { SD }\end{array}$} & $\begin{array}{l}\text { Females } \\
\text { mean } \pm \text { SD }\end{array}$ \\
\cline { 2 - 7 } & Rt $(50)$ & Lt $(50)$ & Rt $(50)$ & Lt $(50)$ & Rt & Lt \\
\hline Mt 1 & $6.81 \pm 0.29$ & $6.39 \pm 0.63$ & $5.83 \pm 0.69$ & $5.46 \pm 0.28$ & $<0.00^{*}$ & $<0.00^{*}$ \\
\hline Mt 2 & $7.74 \pm 0.53$ & $7.92 \pm 0.75$ & $6.36 \pm 0.46$ & $6.44 \pm 0.38$ & 0.33 & $0.00^{*}$ \\
\hline Mt 3 & $7.88 \pm 0.52$ & $7.70 \pm 0.55$ & $6.29 \pm 0.51$ & $6.57 \pm 0.40$ & 0.89 & $0.03^{*}$ \\
\hline Mt 4 & $7.83 \pm 0.29$ & $7.63 \pm 0.39$ & $6.17 \pm 0.46$ & $6.46 \pm 0.35$ & $0.00^{*}$ & 0.45 \\
\hline Mt 5 & $7.41 \pm 0.49$ & $7.23 \pm 0.83$ & $6.02 \pm 0.42$ & $6.15 \pm 0.18$ & 0.28 & $<0.00^{*}$ \\
\hline PP1 & $3.18 \pm 0.40$ & $3.35 \pm 0.36$ & $2.57 \pm 0.18$ & $2.40 \pm 0.37$ & $0.00^{*}$ & 0.85 \\
\hline DP1 & $2.34 \pm 0.14$ & $2.52 \pm 0.13$ & $2.12 \pm 0.17$ & $1.99 \pm 0.19$ & 0.18 & $0.01^{*}$ \\
\hline PP2 & $3.06 \pm 0.27$ & $3.14 \pm 0.26$ & $2.18 \pm 0.21$ & $2.19 \pm 0.33$ & 0.08 & 0.09 \\
\hline MP2 & $1.24 \pm 0.39$ & $0.95 \pm 0.26$ & $0.82 \pm 0.23$ & $0.83 \pm 0.42$ & $0.00^{*}$ & $0.00^{*}$ \\
\hline DP2 & $0.79 \pm 0.11$ & $0.67 \pm 0.20$ & $0.79 \pm 0.48$ & $0.68 \pm 0.44$ & $<0.00^{*}$ & $<0.00^{*}$ \\
\hline PP3 & $2.82 \pm 0.23$ & $2.35 \pm 1.16$ & $1.69 \pm 0.44$ & $1.86 \pm 0.48$ & $0.00^{*}$ & $<0.00^{*}$ \\
\hline MP3 & $1.06 \pm 0.33$ & $0.96 \pm 0.32$ & $0.92 \pm 0.28$ & $0.76 \pm 0.26$ & 0.25 & 0.15 \\
\hline DP3 & $0.85 \pm 0.15$ & $0.75 \pm 0.17$ & $0.45 \pm 0.22$ & $0.66 \pm 0.26$ & $0.08^{*}$ & $0.00^{*}$ \\
\hline PP4 & $2.34 \pm 0.85$ & $2.67 \pm 0.22$ & $1.79 \pm 0.31$ & $1.81 \pm 0.37$ & $<0.00^{*}$ & $0.00^{*}$ \\
\hline MP4 & $0.57 \pm 0.13$ & $0.74 \pm 0.14$ & $0.54 \pm 0.20$ & $0.57 \pm 0.23$ & $0.00^{*}$ & $0.00^{*}$ \\
\hline DP4 & $0.83 \pm 0.11$ & $0.74 \pm 0.23$ & $0.58 \pm 0.29$ & $0.51 \pm 0.16$ & $<0.00^{*}$ & $0.01^{*}$ \\
\hline PP5 & $2.32 \pm 0.23$ & $2.59 \pm 0.32$ & $1.69 \pm 0.15$ & $1.76 \pm 0.12$ & $0.00^{*}$ & $<0.00^{*}$ \\
\hline MP5 & $0.52 \pm 0.08$ & $0.68 \pm 0.35$ & $0.49 \pm 0.16$ & $0.47 \pm 0.14$ & $0.00^{*}$ & $<0.00^{*}$ \\
\hline & & & & & & \\
\hline
\end{tabular}


Citation: Samah Mohammed, et al., Metric and Non metric characteristics of human forefoot: A radiological study in Egyptian population. Australian Journal of Basic and Applied Sciences, 13(2): 46-54. DOI: 10.22587/ajbas.2019.13.2.6

\begin{tabular}{|l|l|l|l|l|l|l|}
\hline DP5 & $0.63 \pm 0.16$ & $0.51 \pm 0.11$ & $0.52 \pm 0.13$ & $0.45 \pm 0.08$ & 0.15 & $0.03^{*}$ \\
\hline
\end{tabular}

Mt1, Mt2, Mt3, Mt4 and Mt5 - First, Second, Third, Fourth and Fifth metatarsals respectively. PP - Proximal Phalanx, MP Middle Phalanx, DP - Distal Phalanx, SD - Standard Deviation, RT=right Lt=left $\mathrm{SD}=$ standard deviation $*=$ significance $(\mathrm{p}<0.05)$

For Widths:

Measurement of the widths of metatarsal revealed that the widest metatarsal in male subjects was Lt Mt1 followed by Rt Mt1 and narrowest one was Rt Mt3. In Female subjects the widest metatarsal was Lt Mt1 followed by Rt Mt1 and the narrowest was Rt Mt4. Statistical analysis of the metatarsal widths for both sides of both sexes revealed that there are sex differences for all metatarsal widths except Lt Mt1, Rt Mt2, Lt Mt2, Rt Mt5 and Lt Mt5 (Table 2). Measurement of the width of PP revealed that the widest PP in male subjects was Lt PP1 followed by Rt PP1 and narrowest one was Rt PP3. In Female subjects the widest PP was Rt PP1 followed by Lt PP1 and the narrowest was Rt PP4.

Measurement of the width of MP revealed that the widest MP in male subjects was Lt MP2 followed by Rt MP2 and narrowest one was Rt MP5. In Female subjects the widest MP was Lt MP2 followed by Lt MP3 and the narrowest was Rt MP4

Measurement of the width of DP revealed that the widest DP in male subjects was Lt DP1 followed by Rt DP1 and narrowest one was Rt DP3. In Female subjects the widest DP was Rt DP1 followed by Lt DP1 and the narrowest was Rt DP4

Statistical analysis of the phalangeal widths for both sides of both sexes revealed that there are sex differences for all phalanges widths except Rt PP1, Rt DP1, Rt PP2, Rt PP3, Lt DP3, Lt MP4and Rt MP5 (Table 2).

Table 2: Student t-test of the forefoot bones widths for both sexes by side

\begin{tabular}{|l|l|l|l|l|l|l|}
\hline \multirow{2}{*}{ Variables } & \multicolumn{2}{l}{$\begin{array}{l}\text { Males } \\
\text { mean } \pm \text { SD }\end{array}$} & \multicolumn{2}{l|}{$\begin{array}{l}\text { Pemales } \\
\text { mean } \pm \text { SD }\end{array}$} \\
\cline { 2 - 7 } & Rt $(50)$ & Lt $(50)$ & Rt $(50)$ & Lt $(50)$ & Rt & Lt \\
\hline Mt 1 & $1.42 \pm 0.20$ & $1.48 \pm 0.08$ & $0.91 \pm 0.11$ & $0.94 \pm 0.07$ & $0.00^{*}$ & 0.35 \\
\hline Mt 2 & $0.63 \pm 0.17$ & $0.68 \pm 0.09$ & $0.62 \pm 0.14$ & $0.63 \pm 0.08$ & 0.18 & 0.41 \\
\hline Mt 3 & $0.56 \pm 0.10$ & $0.60 \pm 0.10$ & $0.58 \pm 0.05$ & $0.68 \pm 0.16$ & $0.00^{*}$ & $0.00^{*}$ \\
\hline Mt 4 & $0.69 \pm 0.14$ & $0.68 \pm 0.07$ & $0.50 \pm 0.10$ & $0.61 \pm 0.11$ & $0.02^{*}$ & $0.00^{*}$ \\
\hline Mt 5 & $0.79 \pm 0.08$ & $0.70 \pm 0.19$ & $0.55 \pm 0.08$ & $0.70 \pm 0.17$ & 1.00 & 0.44 \\
\hline PP1 & $1.11 \pm 0.11$ & $1.28 \pm 0.11$ & $0.95 \pm 0.10$ & $0.69 \pm 0.33$ & 0.51 & $<0.00^{*}$ \\
\hline DP1 & $0.93 \pm 0.13$ & $1.04 \pm 0.15$ & $0.77 \pm 0.13$ & $0.75 \pm 0.07$ & 1.00 & $0.00^{*}$ \\
\hline PP2 & $0.59 \pm 0.09$ & $0.55 \pm 0.08$ & $0.49 \pm 0.07$ & $0.41 \pm 0.22$ & 0.08 & $<0.00^{*}$ \\
\hline MP2 & $0.66 \pm 0.13$ & $0.67 \pm 0.12$ & $0.51 \pm 0.08$ & $0.58 \pm 0.09$ & $0.00^{*}$ & $0.05^{*}$ \\
\hline DP2 & $0.44 \pm 0.16$ & $0.49 \pm 0.12$ & $0.41 \pm 0.05$ & $0.42 \pm 0.05$ & $<0.00^{*}$ & $<0.00^{*}$ \\
\hline PP3 & $0.43 \pm 0.13$ & $0.46 \pm 0.13$ & $0.56 \pm 0.10$ & $0.50 \pm 0.07$ & 0.07 & $0.00^{*}$ \\
\hline MP3 & $0.62 \pm 0.18$ & $0.64 \pm 0.16$ & $0.47 \pm 0.08$ & $0.55 \pm 0.11$ & $<0.00^{*}$ & $0.01^{*}$ \\
\hline DP3 & $0.41 \pm 0.08$ & $0.48 \pm 0.06$ & $0.30 \pm 0.11$ & $0.37 \pm 0.07$ & $0.03^{*}$ & 0.28 \\
\hline PP4 & $0.44 \pm 0.13$ & $0.45 \pm 0.06$ & $0.34 \pm 0.05$ & $0.41 \pm 0.09$ & $<0.00^{*}$ & $0.01^{*}$ \\
\hline MP4 & $0.65 \pm 0.10$ & $0.61 \pm 0.10$ & $0.40 \pm 0.05$ & $0.44 \pm 0.08$ & $0.00^{*}$ & 0.12 \\
\hline DP4 & $0.42 \pm 0.11$ & $0.50 \pm 0.17$ & $0.28 \pm 0.06$ & $0.40 \pm 0.10$ & $0.00^{*}$ & $0.00^{*}$ \\
\hline PP5 & $0.50 \pm 0.11$ & $0.48 \pm 0.14$ & $0.36 \pm 0.06$ & $0.38 \pm 0.10$ & $0.00^{*}$ & $0.02^{*}$ \\
\hline MP5 & $0.57 \pm 0.11$ & $0.59 \pm 0.16$ & $0.53 \pm 0.12$ & $0.53 \pm 0.06$ & 0.55 & $<0.00^{*}$ \\
\hline DP5 & $0.47 \pm 0.19$ & $0.46 \pm 0.18$ & $0.34 \pm 0.10$ & $0.35 \pm 0.09$ & $0.00^{*}$ & $0.00^{*}$ \\
\hline Mt1 Mt2
\end{tabular}

Mt1, Mt2, Mt3, Mt4 and Mt5 - First, Second, Third, Fourth and Fifth metatarsals respectively. PP - Proximal Phalanx, MP Middle Phalanx, DP - Distal Phalanx, SD - Standard Deviation, RT=right Lt=left $\mathrm{SD}=$ standard deviation $\quad *=$ significance $(\mathrm{p}<0.05)$

Correlation coefficient for metatarsal lengths

Correlation coefficient between lengths of metatarsals amongst themselves were recorded and presented for males and female subjects (Table 3). In male's correlation coefficient between lengths of metatarsals amongst themselves showed that most of the variables show significant strong positive correlation with each other. The highest significant correlation was between Mt4 and Mt5 (r=0.93). Also, Mt1 showed highest significant association with Mt5 ( $\mathrm{r}=0.82)$ thus the length of the metatarsals can be predicted (Table 3). In female's correlation coefficient between lengths of metatarsals amongst themselves showed that Mt1 correlated significantly and positively with Mt2, Mt3, Mt5 thus the length of the Mt1 can be predicted from these metatarsals. However, it showed significant negative correlation with Mt4. No other significant association was found (Table 3).

Table 3: Correlation matrix for lengths of metatarsals amongst themselves in male and female subjects

\begin{tabular}{|c|c|c|c|c|c|c|c|c|}
\hline & Males & & & & Female & & & \\
\hline & Mt2 & Mt3 & Mt4 & Mt5 & Mt2 & Mt3 & Mt4 & Mt5 \\
\hline
\end{tabular}


Citation: Samah Mohammed, et al., Metric and Non metric characteristics of human forefoot: A radiological study in Egyptian population. Australian Journal of Basic and Applied Sciences, 13(2): 46-54. DOI: 10.22587/ajbas.2019.13.2.6

\begin{tabular}{|l|l|l|l|l|l|l|l|l|}
\hline Mt1 & $\begin{array}{l}0.76 \\
(0.00)\end{array}$ & $\begin{array}{l}0.76 \\
(0.00)\end{array}$ & $\begin{array}{l}0.72 \\
(1.00)\end{array}$ & $\begin{array}{l}0.82 \\
(0.00)\end{array}$ & $\begin{array}{l}0.32 \\
(0.00)\end{array}$ & $\begin{array}{l}0.07 \\
(0.04)\end{array}$ & $\begin{array}{l}-0.21 \\
(0.00)\end{array}$ & $\begin{array}{l}0.43 \\
(0.02)\end{array}$ \\
\hline Mt2 & - & $\begin{array}{l}0.70 \\
(0.89)\end{array}$ & $\begin{array}{l}0.62 \\
(0.00)\end{array}$ & $\begin{array}{l}0.81 \\
(0.59)\end{array}$ & - & $\begin{array}{l}0.48 \\
(0.47)\end{array}$ & $\begin{array}{l}0.61 \\
(1.00)\end{array}$ & $\begin{array}{l}0.88 \\
(0.66)\end{array}$ \\
\hline Mt3 & - & - & $\begin{array}{l}0.87 \\
(0.00)\end{array}$ & $\begin{array}{l}0.86 \\
(0.68)\end{array}$ & - & - & $\begin{array}{l}0.55 \\
(0.47)\end{array}$ & $\begin{array}{l}0.67 \\
(0.78)\end{array}$ \\
\hline Mt4 & - & - & & $\begin{array}{l}0.93 \\
(0.00)\end{array}$ & - & - & - & $\begin{array}{l}0.58 \\
(0.66)\end{array}$ \\
\hline
\end{tabular}

MT1, MT2, MT3, MT4 and MT5 - First, Second, Third, Fourth and Fifth metatarsals respectively. P- Values are shown in parentheses

Correlation coefficient for metatarsal widths

Correlation coefficient between widths of metatarsals amongst themselves were recorded and presented for males and female students (Table 4). In males correlation coefficient between widths of metatarsals amongst themselves showed that most of the variables showed fair positive significant correlation with each other. Mt1 showed weak negative correlation with Mt4 and Mt5. The highest significant association was found between Mt4 and Mt5 ( $\mathrm{r}=0.61)$ (Table 4). In females correlation coefficient between widths of metatarsals amongst themselves showed that Mt1 negatively correlated with all other metatarsals also Mt 2 negatively correlated with Mt5. Other variables showed fair to moderate significant positive correlation. The highest significant correlation was between Mt3 and Mt4 (r=0.63) (Table 4).

Table 4: Correlation matrix for widths of metatarsals amongst themselves in male and female subjects

\begin{tabular}{|l|l|l|l|l|l|l|l|l|}
\hline & Males & \multicolumn{7}{l|}{ Females } \\
\hline & Mt2 & Mt3 & Mt4 & Mt5 & Mt2 & Mt3 & Mt4 & Mt5 \\
\hline Mt1 & 0.26 & 0.38 & -0.12 & -0.01 & -0.41 & -0.04 & -0.28 & -0.33 \\
& $(0.21)$ & $(0.00)$ & $(0.01)$ & $(<0.00)$ & $(0.09)$ & $(0.00)$ & $(0.51)$ & $(0.03)$ \\
\hline Mt2 & - & 0.50 & 0.22 & 0.31 & - & 0.08 & 0.55 & -0.00 \\
& & $(0.00)$ & $(0.18)$ & $(0.00)$ & & $(<0.00)$ & $(0.02)$ & $(0.00)$ \\
\hline Mt3 & - & - & 0.60 & 0.68 & - & - & 0.63 & 0.54 \\
& & & $(0.02)$ & $(0.12)$ & & & $(0.00)$ & $(0.00)$ \\
\hline Mt4 & - & - & - & 0.61 & - & - & - & 0.67 \\
& & & & $(0.00)$ & & & & $(0.12)$ \\
\hline
\end{tabular}

MT1, MT2, MT3, MT4 and MT5 - First, Second, Third, Fourth and Fifth metatarsals respectively. P- Values are shown in parentheses

\section{DISCUSSION}

$\mathrm{X}$ ray procedures allow rapid, costless and easy visualization of skeletal system with little drawbacks (Domínguez-Maldonado et al., 2014). Ossification of bones of foot doesn't happen until age of 15 and 17 in male and female subjects respectively. Fusion of epiphysis is completed at 20 years old (Kleiger et al., 1982). Therefore, subjects less than 21 years old were excluded in the present study. In the present study The PP showed concave medial and lateral margins. There was no morphological deviation of this appearance concerning PP margins of different digits. The length of the PP is always greater than its width. This is similar to (Keats and Anderson, 2013) who noted that the PP bone is always of an elongated type. The traditional morphological appearance of PP may be due to that PP always have secondary center of ossification (Billmann and Le Minor, 2007). In the present study the MP showed variations in its antero-posterior distance. As the length of the bone may be greater than its width, equal or even less. Variable appearance of MP leads to description of middle phalanx as elongated type or shortened type. This is in accordance with (Jouffroy and Lessertisseur, 1977 and Le Minor et al., 2016)) who reported that the pattern of toes reduction concerning the MP is unique in human being. It was not noted for other primates before. The MP may not have well-recognized nutrient foramina and get its blood supply through periosteal blood vessels (Mysorekar and Nandedkar, 1979). This may explain in part the variable morphology of elongated and short type of MP noted in the present study. The middle phalanges seem to have a key role in the specific evolution of human lateral toes (Le Minor et al., 2016). In the present study the $5^{\text {th }}$ digit was presented only with shortened type of MP and no cases were reported with elongated type. This is in agreement with (Le Minor et al., 2016) who reported that MP of the 5th toe if present was only of shortened type. It was an interesting to note that most of elongated MP was having concave medial and lateral margins while most of the shortened type was having flat to convex margins. This description is similar to (Christman, 2003) who reported the borders of rectangular MP may appear straight or curved. In the present study convexity of lateral margins in some of MP of $5^{\text {th }}$ toe was noted giving it a rounded appearance. To the best of our knowledge this is rounded type wasn't described before.

Absence of MP in the $4^{\text {th }}$ and $5^{\text {th }}$ digits was reported in the present study. The $4^{\text {th }}$ digit or $5^{\text {th }}$ digits with absent MP were described as having biphalangeal pattern. The secondary center of ossification may play a significant role in occurrence of this pattern (Billmann and Le Minor, 2007). The occurrence of biphalangeal digit varies geographically. The highest occurrence was reported for Japanese (72.5- 80.4\%) was reported (Nakashima et al. 1995). In the present study the DP showed no morphological variation concerning DP of different digits. They have wide base and tapered head. There was no digit without DP. These observations are 
Citation: Samah Mohammed, et al., Metric and Non metric characteristics of human forefoot: A radiological study in Egyptian population. Australian Journal of Basic and Applied Sciences, 13(2): 46-54. DOI: 10.22587/ajbas.2019.13.2.6

similar to those reported by (Billmann and Le Minor, 2007) who noted no major morphological differences in DP in all toes. However, the DP may be rudimentary or absent in other primates (Jouffroy and Lessertisseur, 1977). In the present study Lt Mt2 was the longest one in both sexes. This is in accordance with (Patil et al., 2017) who reported that the second metatarsal bone was the longest one. On the other hand, in a study done by (Dogan et al., 2007) recorded that the longest metatarsal bone was the fifth one. This difference may be due to different reference points for length measuring technique. Some authors consider the margin of styloid process of the $5^{\text {th }}$ metatarsal in measuring $5^{\text {th }}$ metatarsal length. The present study reported that the shortest metatarsal bone to be Lt Mt1 in both sexes. This is in accordance with both (Dogan et al., 2007; Patil et al., 2017). In the present study the mean length value of Mt1 for males was $6.81 \pm 0.29 \mathrm{~cm}$ and $6.39 \pm 0.63 \mathrm{~cm}$ for right and left side respectively. The mean length value of Mt1 for females was $5.83 \pm 0.69$ and $5.46 \pm 0.28 \mathrm{~cm}$ for right and left side respectively. These values are higher than those reported by (Patil et al., 2017) who reported a mean length of first metatarsal bones were $56.42 \pm 4.41 \mathrm{~mm}$ and $50.09 \pm 3.06 \mathrm{~mm}$ in males and females respectively. Also mean values for Mt2 length in the present study were higher than those reported by (Patil et al., 2017). This difference may be in part due to different races and or different methodological techniques. In the present study the widest metatarsal in male and female subjects was Lt Mt1. This is in accordance with both (Abdel Moneim et al., 2008; Dogan et al., 2007 and Patil et al., 2017). In general the $1^{\text {st }}$ metatarsal bone is thickest and shortest one. This is in accordance to (Mann, 1999) who stated that the first metatarsal bone is the shortest and thickest and plays an important role during propulsion as many tendons attached to it. On the other hand the second, third, and fourth metatarsal bones are the most stable of the metatarsals. They are well-protected and have only minor tendon attachments. These characteristics of $1^{\text {st }}$ metatarsal bone adapt it for weight bearing capacity of $1^{\text {st }}$ metatarsal which is double that of any other metatarsals (Viladot, 1973). The narrowest metatarsal was Rt Mt3 and lt Mt4 in male and female subjects respectively. In a study done by (Dogan et al., 2007 and Patil et al., 2017) the narrowest metatarsal was Mt3. However, (Abdel Moneim et al., 2008) reported that the narrowest metatarsal to be $5^{\text {th }}$ and $2^{\text {nd }}$ metatarsal for male and female subjects respectively. In the present study the longest phalanx was reported to be Lt PP1 and Rt PP1 in male and female subjects respectively. Also both (Dogan et al., 2007 and Patil et al., 2017) reported similar finding. The mean value of PP1 was higher in the present study than that recorded by (Patil et al., 2017). The Lt DP5 was reported to be the shortest one followed by Lt MP5 in the present study. The same finding was reported by (Patil et al., 2017). However, (Dogan et al., 2007) reported the $5^{\text {th }}$ MP to be the shortest. The short lengths of the phalanges add to proper locomotors function of the foot by decreasing load of muscles responsible for digit flexion and make locomotor function much better (Mann, 1999).Measuring forefoot bone dimensions is important for evaluating the severity of a disorder, the choice of suitable procedure, achieving proper surgery outcome, and post-surgery evaluation (Patil et al., 2017). Changes in metatarsal lengths may result in motor limitations. As the heads of metatarsals are load bearing. Knowledge of the lengths of all metatarsal bones and its correlation with each other is of surgical importance especially osteotomy. Proper osteotomy needs proper length determination (John et al., 2015). Knowledge of the lengths of metatarsal bone is important for surgeons both before and after surgical procedures in foot. As it helps in determination proper osteotomy length, proper uniformity of the elongated metatarsal and bypass prospect complication (Scher et al., 2010). After surgery length determination is important to assess the degree of osteotomy success and the probability of subsequent pain arising from operated metatarsal (Lee et al., 2015). Correlation coefficient was carried out to examine the possibility of calculation of metatarsal length using the lengths of other metatarsals. In the present study there were significant positive correlation regarding metatarsal lengths among themselves. This is important in patients need resection of metatarsal heads secondary to deformed foot due to diabetes or rheumatic diseases. Resection of metatarsal heads affect the anatomy of medial longitudinal arch impairing foot function with resultant pain (Murphy, 2013). This highlights the importance of knowing this relation pre and post-operative. In the present study most of metatarsal and phalangeal lengths were greater in male than females with significant difference except length of Dp2 which were longer in female subjects than male subjects. Also (Abdel Moneim et al., 2008) in his study reported that metatarsal length in male subjects is greater than that of female subjects and thus it is of value in sex discrimination. In the present study males were having wider metatarsal and phalanges except for width of Mt3. These findings are in accordance with those reported by (Akhlaghil et al., 2017) who found both bones mean length and width are greater in male subjects than female subjects. Also, Patil et al., (2017) reported a significant metric value difference between male and females. Size is the basic anatomical differences between the male and female skeletal system and this difference is well documented. For example, the male subjects have larger skulls with well-defined bony prominence such as glabella, supraorbital ridge, inion, occipital condyles, mastoid and styloid process, and men have bigger bones of the hindfoot and forefoot on the other hand female subjects have wider pelvic cavity (Domínguez-Maldonado et al., 2014). However, mean values obtained must be population based. Specific population-based values can be used for sex recognition and not that of others (Akhlaghi1 et al., 2017).

\section{CONCLUSION AND RECOMMENDATION}

The dimensions of the forefoot bones and their correlation within themselves are important determinants for the proper function of the lower extremity. Hence, they are important for both surgical application and sex recognition. The correlations between forefoot bones enable practitioners to calculate the proper length of other forefoot bones. The morphology of forefoot bone may add to proper surgical procedures or sex recognition. Further study comparing sex difference based on forefoot morphology may be interesting.

\section{LIMITATION OF THE STUDY}

A lager sample is required to give authoritative data for Egyptian population

\section{ACKNOWLEDGMENTS}

Many thanks to all anatomy department staff members and all participants in this study. 
Citation: Samah Mohammed, et al., Metric and Non metric characteristics of human forefoot: A radiological study in Egyptian population. Australian Journal of Basic and Applied Sciences, 13(2): 46-54. DOI: 10.22587/ajbas.2019.13.2.6

Abdel Moneim, W.M., R.H. Abdel Hady, R.M. Abdel Maaboud, H.M. Fathy, A.M. Hamed, 2008. Identification of sex depending on radiological examination of foot and patella. Am J Forensic Med Pathol., 29(2):136-140.

Akhlaghi1, M., K. Bakhtavar, H. Bakhshandeh, Mokhtari, T. Farahani, V.A. Parsa, F. Mehdizadeh, M.H. Sadegh, 2017. Sex Determination Based on Radiographic Examination of Metatarsal Bones in Iranian Population. International journal of medical toxicology and clinical forensic, 7(4).

Al Abdulwahab, S.S., and S.J. Kachanathu, 2015. The effect of various degrees of foot posture on standing balance in a healthy adult population. Somatosensory and Motor Research, 32(3):172-76.

Billmann, F., and J.M. Le Minor, 2007. Secondary centers of ossification of the human toes: exceptional polymorphism and evolutionary perspectives. Am J Phys Anthropol, 132, 110-118.

Christman, R.A, 2003. Normal variants and anomalies. In: Foot and Ankle Radiology. (ed. Christman RA), pp. 142-187. St Louis: Churchill Livingstone.

Dogan, A., M. Uslu, A. Aydinlioglu, M. Harman, F. Akpinar, 2007. Morphometric study of the human metatarsals and phalanges. Clin Anat, 20:209-214.

Domínguez-Maldonado, G., P.V. Munuera-Martinez, J.M. Castillo-López, J. Ramos-Ortega, M. Albornoz-Cabello, 2014. Normal values of metatarsal parabola arch in male and female feet. The Scientific World Journal, ID 505736.

Green, J.S., P.S. Parfrey, J.D. Harnett, N.R. Farid, B.C. Cramer, G. Johnson, O. Heath, P.J. McManamon, E. O’Leary, W. PrysePhillips, 1989. The cardinal manifestations of Bardet-Biedl syndrome, a form of Laurence-Moon-Biedl syndrome. N Engl J Med, 321:1002-1009.

John, V., K.K. Panagiotis, V. Polizois, E.S. Dimitrios, P.G. Spyridon, 2015. Preservation of the length of the first metatarsal after modified Mitchell's osteotomy for hallux valgus deformity. Overview, technique and preliminary results. Clin Res Foot Ankle, 3:164

Jouffroy, F.K., J. Lessertisseur, 1977. Processus de reduction des doigts (main et pied) chez les Primates. Modalites, implications genetiques. In: Mecanismes de la Rudimentation des Organes chez les Embryons des Vertebr es. (ed. Raynaud A), pp. 381-392. Paris: CNRS

Keats, T.E., M.W. Anderson, 2013. Atlas of Normal Roentgen Variants that may Simulate Disease, 9th edn. Philadelphia: Saunders-Elsevier._eBook ISBN: 9780323091282

Kleiger, B., A. Greenspan, A. Norman, 1982. Roentgenographic examination of the normal foot and ankle. In: Jahss MH. Disorders of the foot. Philadelphia: Saunders, p. 116-138.

Lamm, B.M, 2006. Limb Lengthening and Reconstruction Surgery. New York: CRC Press, Metatarsal Lengthening. In: Rozbruch SR, Ilizarov S, editors; pp. 291-301.

Lamm, B.M., D. Paley, J.E. Herzenberg, 2009. Minimally Invasive Surgery in Orthopaedics. New York: Springer Science \& Business Media; Percutaneous distraction osteogenesis for treatment of brachymetatarsia. In Scuderi GR, Tria AJ, editors, pp. 435-442.

Lee, J.Y., Y.S. Lee, K.C. Song, K.Y. Choi, 2015. Change in first metatarsal length after proximal and distal chevron osteotomies for hallux valgus deformity. J Foot Ankle Surg, 54(4):525-530

Le Minor, J.M., J.F. Mousson, P. de Mathelin, G. Bierry, 2016. Non-metric variation of the middle phalanges of the human toes (II-V): long/short types and their evolutionary significance. J. Anat, 228, pp. 965--974

Mann, R.A, 1999. Biomechanics of the foot and ankle. In: Coughlin MJ, Mann RA, editors. Surgery of the Foot and Ankle, St Louis: Mosby. p 2-35.

Murphy, G.A, 2013. Campbell's Operative Orthopaedics. 12th ed. Philadelphia: Elsevier Mosby, Lesser toe abnormalities 39794026.

Mysorekar, V.R, and A.N. Nandedkar, 1979. Diaphysial nutrient foramina in human phalanges. J Anat, 128, $315-322$.

Nakashima, T., T. Hojo, K. Suzuki, et al., 1995. Symphalangism (two phalanges) in the digits of the Japanese foot. Ann Anat, 177, 275-278.

Nawoczenski, D.A., C.L. Saltzman, T.M. Cook, 1998. The effect of foot structure on the three-dimensional kinematic coupling behavior of the leg and rear foot. Phys Ther, 78:404-16.

Patil, S., G.H. Hanumantharaya, S.P. Desai, and M. Nidoni, 2017. Radiological Biometric Study of Metatarsals and Phalanges. J Clin Diagn Res, 11(9): AC05-AC09.

Rolian, C., D.E. Liberman, J. Hamill, J.W. Scott, W. Werbel, 2009. Walking, running and the evolution of short toes in humans. Journal of Experimental Biology, 212: 713-721

Scher, D.M., A. Blyakher, M. Krantzow, 2010. A modified surgical technique for lengthening of a metatarsal using an external fixator. HSS Journal, 6(2):235-239

Viladot, A., 1973. Metatarsalgia due to biomechanical alterations of the forefoot. Orthop Clin North Am, 4:165-178. 